\title{
NILAI RELIGIOSITAS DALAM NOVEL HOMOSEKS KETEMU TUHAN KARYA RINI KRISTINA
}

\author{
Ika Febriani \\ Universitas Trunojoyo Madura \\ Email: ikafebrianiutm14@gmail.com
}

\begin{abstract}
Abstrak
Novel Homoseks Ketemu Tuhan menceritakan tentang seorang sang tokoh utama terdampar di desa tersebut. Ia menjalani detik-detik hidup di dukuh larangan. Ia terjebak, masuk dalam arus hidup yang tak pernah diduga sebelumnya. Perjalanan hidupnya yang berliku memiliki banyak kisah untuk diceritakan. Tokoh utama itu menjalani aktivitas sehari-hari sebagai guru mengaji bagi anak-anak dan orangtua di desa tersebut. Ia seolah menjadi cahaya dalam kegelapan dusun itu. Akhirnya waktu berjalan terus hingga ia terbebas lepas dari kebiasaan buruknya sebagai seorang homoseks. Hal itulah kemenarikan novel Homoseks Ketemu Tuhan. Tujuan penelitian ini untuk mendeskripsikan nilai religiositas dalam novel Homoseks Ketemu Tuhan karya Rini Kristina berdasarkan fungsinya untuk memengaruhi pembaca dalam segi religi. Digunakan nilai religiositas dalam menganalisis novel ini. Dalam metode penelitian digunakan pendekatan kualitatif dengan teknik deskriptif. Hasil penelitian ini adalah nilai religiositas yang mencolok dalam novel Homoseks Ketemu Tuhan karya Rini Kristina ini adalah panggilan agar pembaca menyadari hidupnya sebagai makhluk yang lemah, yang mau berserah diri kepada Allah, Sang Pencipta. Khususnya kepada orang yang termasuk kaum homoseks atau lesbian agar sadar untuk kembali kepada fitrahnya.
\end{abstract}

Kata Kunci: nilai religiositas, novel, amanat.

\section{PENDAHULUAN}

Novel islami banyak bermunculan dalam sastra Indonesia. Dengan berlatar religi novel islami mempertahankan nilai-nilai religiositas dalam karya-karya sastranya. Dengan didukung di dalamnya terdapat nilai kehidupan yang lain makin menambah semarak prosa fiksi saat ini.

Karya sastra diciptakan pengarang dengan berbagai tema yang diangkat. Tema tentang cinta bahkan tentang seksualitas agaknya telah mewarnai karya sastra Indonesia pada dekade ini baik seksualitas normal maupun abnormal.

Sastra merupakan sebuah gambar mengenai kenyataan (Luxemburg dkk. 1986: 19). Sebagai sebuah dunia miniatur, karya sastra berfungsi untuk menginventarisasikan sejumlah besar kejadian-kejadian yang telah dikerangkakan dalam pola-pola kreativitas dan imajinasi (Ratna, 2003: 35). Pendapat tersebut sejalan dengan pernyataan Faruk (2003: 11) bahwa kesusastraan merupakan lembaga sosial.

Sebuah karya sastra, selain merupakan hasil pengalaman batin dan pengalaman estetik, juga sebagai ekspresi diri penulisnya. Salah satu yang dituangkan dalam karya sastra berupa pengalaman estetik yang berhubungan unsur religiositas (Sitanggang dkk, 2003: 1).
Kedatangan seorang ilmuwan Jerman di Desa Cengkehan ternyata menambah kesuraman desa tersebut. Desa tersebut dikenal dengan "dukuh larangan". Dari masa suram pembantaian PKI, kecantikan gadis-gadis yang menggoda lelaki desa lain, hingga munculnya para homoseks setelah kedatangan ilmuwan asal Jerman itu. Mendengar Dusun Cengkehan, banyak orang seperti mendengar sarang setan disebut.

Sang tokoh utama terdampar di desa tersebut. Ia menjalani detik-detik hidup di dukuh larangan. Ia terjebak, masuk dalam arus hidup yang tak pernah diduga sebelumnya. Perjalanan hidupnya yang berliku memiliki banyak kisah untuk diceritakan.

Tokoh utama itu menjalani aktivitas sehari-hari sebagai guru mengaji bagi anak-anak dan orangtua di desa tersebut. Ia seolah menjadi cahaya dalam kegelapan dusun itu. Akhirnya waktu berjalan terus hingga ia terbebas lepas dari kebiasaan buruknya sebagai seorang homoseks.

Kisah hidup tokoh dalam novel Homoseks Ketemu Tuhan karya Rini Kristina menarik diteliti nilai religiositasnya. Hal ini disebabkan tokoh utama yang religius menjadi guru mengaji di sebuah desa yang lama-kelamaan kebiasaan buruk homoseks hilang. 
Mangunwijaya menyatakan bahwa dalam karya sastra terkandung nilai, norma, dan ajaran agama (Sitanggang dkk, 2003: 1). Penelaahan unsur religiositas dalam karya sastra merupakan bidang yang penting diperhatikan secara serius baik tentang kepercayaan terhadap Tuhan Yang Mahaesa maupun yang berkaitan dengan kehidupan masyarakat dalam novel Homoseks Ketemu Tuhan karya Rini Kristina.

Berdasarkan latar belakang tersebut dalam penelitian dideskripsikan nilai religiositas dalam novel Homoseks Ketemu Tuhan karya Rini Kristina.

\section{KONSEP NILAI RELIGIOSITAS}

Religi diartikan lebih luas daripada agama (Atmosuwito, 2010:123). Lebih lanjut menurut Atmosuwito konon religi menurut asal kata berarti ikatan atau pengikatan diri yang bersifat personalitas, hal yang pribadi. Kemudian kata bereligi berarti menyerahkan diri, tunduk, taat.

Kata religiositas berarti pengabdian terhadap agama (KBBI, 2010). Manusia religius secara sederhana diartikan sebagai manusia yang berhati nurani serius, taat, saleh, dan teliti dalam pertimbangan batin (Sitanggang, 2003: 3). Religiositas dalam penelitian ini difokuskan pada karya sastra genre prosa. Sejalan dengan pendapat Ratna (2004: 335) di antara genre utama karya sastra, genre prosalah, khususnya novel, yang dianggap paling dominan dalam menampilkan unsur-unsur sosial.

Konsep religius menurut Ali dkk (dalam Supratno, 2010:373) dapat berarti bersifat religi, bersifat keagamaan yang bersangkut paut dengan religi, sedangkan nilai religiositas yang dimaksud dalam penelitian ini adalah yang ada hubungannya dengan masalah religi yang terdapat dalam novel Homoseks Ketemu Tuhan karya Rini Kristina.

Novel populer merepresentasikan realitas zamannya sekaligus memiliki efek sosiologis yang besar terhadap pembaca (Rosidah, 2003: 39). Novel-novel populer bermunculan dengan tema religius. Mohammad menyatakan bahwa sastra religius adalah sebuah genre sastra yang bermaksud memberikan jawaban pada situasinya dengan berbasiskan nilai-nilai yang bersifat tradisional keagamaan (Sitanggang dkk, 2003: 3). Sejalan dengan pendapat Pradotokusumo (2003:29) dalam sastra bahan diolah secara khusus sehingga dalam hal ini karya sastra dapat dinikmati pembacanya.
Sayuti (1999) menjelaskan bahwa ada tiga wilayah fundamental yang menjadi sumber penciptaan karya sastra yaitu wilayah kehidupan agama, sosial, dan individual. Karenanya, karya dapat berfungsi sebagai alat untuk meneguhkan dan mengukuhkan suasana batin pembaca dalam menjalankan keyakinan agamanya (Sitanggang dkk, 2003: 3-4). Karya sastra jelas bertolak dari pengalaman sastrawan, baik pengalaman yang diperoleh dalam interaksi sosial maupun pengalaman dari interaksi religiusnya (Jabrohim, 2003:158).

Dalam penelitian ini dianalisis nilai-nilai religiositas dan amanat yang terkandung dalam novel Homoseks Ketemu Tuhan karya Rini Kristina. Penganalisisan ini berdasarkan data yang terdapat dalam novel tersebut.

\section{METODE PENELITIAN}

Dalam metode penelitian digunakan pendekatan kualitatif dengan teknik deskriptif. Hal ini sejalan dengan pendapat Triyono (Jabrohim (Ed.), 2003:23) bahwa dalam penelitian sastra digunakan teknik kualitatif yang menitikberatkan pada segi alamiah dan mendasarkan pada karakter yang terdapat dalam data.

Teknik pengumpulan data digunakan teknik baca, teknik catat, dan teknik pustaka disebabkan dalam penelitian ini kepustakaan digunakan sesuai dengan kondisi data dan kepentingan penelitian, bukan penelitian lapangan. Teknik penganalisisan data digunakan teknik menginterpretasi dan menyimpulkan dengan mendeskripsikan nilai religiositas dalam novel Homoseks Ketemu Tuhan karya Rini Kristina.

\section{PEMBAHASAN \\ Nilai Religiositas dalam Novel Homoseks Ketemu Tuhan Karya Rini Kristina}

Sebagai makhluk yang diciptakan paling sempurna dan paling mulia sudah selayaknya manusia hidup bertakwa kepada Tuhan. Ini sejalan dengan pendidikan karakter dan akhlak di Indonesia yang kini kian memprihatinkan.

Koentjaraningrat (1984) mengemukakan bahwa dalam suatu masyarakat terdapat dua kelompok, yaitu masyarakat agamis dan sinkretis (Sitanggang dkk, 2003: 121). Lebih lanjut dijelaskan bahwa kelompok masyarakat sinkretis mencampuradukkan ajaran agama dengan kepercayaan yang mereka yakini.

Nilai religiositas ketakwaan kepada Sang Pencipta tampak menonjol dalam novel 
Homoseks Ketemu Tuhan karya Rini Kristina. Melalui tokoh-tokohnya, Rini Kristina menggambarkan penafsiran mengenai ketakwaan kepada Tuhan.

Badrud, tokoh utama dalam novel ini meyakini bahwa sebagai seorang penganut agama Islam, ketakwaan tidak hanya melaksanakan semua kewajiban yang diperintahkan oleh Tuhan (seperti salat lima waktu, mengaji, dan berdoa) serta menjauhi larangan-larangan-Nya tetapi juga harus bekerja. Hal yang diyakini itu terasa tidak mudah menjalankannya.

Badrud dikisahkan sebagai seorang homoseks yang diketahui umum tidak diperbolehkan dalam agama Islam. Manusia hidup harus berpasang-pasang antara orang yang satu dengan orang yang lain jenis kelamin.

Badrud paham tentang agama bahkan ia dipercaya sebagai guru ngaji di kampung tempat ia tinggal. Dikisahkan dalam novel bahwa sewaktu sekolahnya dulu ia menyukai teman sejenis. Entah apa yang membuat hal ini bisa terjadi pada diri Badrud. Badrud lebih menyukai teman lelakinya dan tidak tergoda dengan perempuan sebagaimana kutipan novel berikut.

Usai membakar jagung tiga buah, badrud memilih baca di kamar untuk menghindari godaan teman ceweknya. Tak lama kemudian Raka muncul. Cowok terkece di kelas itu duduk di samping Badrud.

"Dicari Hesti sama Dani tuh!"

"Males ah."

Badrud tersentak ketika tangan Raka mengusap pahanya. Ia membuka mata.

Namun dengan sigap Raka membungkam mulutnya. Badrud mencoba berontak, namun tubuhnya kalah kuat. Ia tak berdaya. Malam itu ia tak kuasa menolak keinginan Raka. Berbagai rasa berbaur di dalam benaknya. Yang pasti ia sangat sedih dan malu. Merasa diri tak berharga (Kristina, 2011: 131).

Berdasarkan penggalan novel di atas Badrud merasa dirinya sebagai seorang muslim tidak memiliki harga diri karena telah melakukan dosa. Ia sadar dan ingin kembali ke jalan yang benar dengan tidak menjadi kaum homoseks. Hal itu terus diupayakan olehnya sebagaimana kutipan berikut.

Badrud dicekam rasa berdosa dan berniat kembali kepada fitrahnya. Ia memulainya dengan kos sendiri, namun ia belum mampu sepenuhnya putus dengan Raka. Cintanya ada pemuda itu masih membara. Kematian kakaknya menyadarkan Badrud agar segera mengakhiri perilaku gay-nya (Kristina, 2003: 132-133).

Dikisahkan dalam dalam novel Homoseks Ketemu Tuhan karya Rini Kristina bahwa Badrud berupaya dengan menjadi guru mengaji di desa Cengkehan. Ia menerima tawaran warga dengan mengajarkan mengaji kepada warga desa tersebut baik anak-anak maupun orangtua yang ingin bisa mengaji. Ia sangat bersyukur kepada Allah karena diberi ladang beramal. Hal tersebut sebagaimana dalam kutipan berikut.

"Pak Huda itu pintar ngaji, pasti Sampeyan juga gitu. Pak Huda dulu menyempatkan muruk ngaji bocahbocah, usai salat maghrib di langgar. Begitu Pak Huda pergi tak ada lagi yang muruk. Maklum, kami ini kan warga desa yang bodoh.

"Kalau bersedia, nanti Sampeyan langsung saja ke langgar pas maghrib, nanti anak-anak saya beri tahu"

Badrud manggut. Ia sangat bersyukur Allah telah memberi jalan untuk mengamalkan ilmunya (Kristina, 2003: 19-20).

Nilai religiositas digunakan Kristina dalam novel Homoseks Ketemu Tuhan tidak hanya pada perilaku tokoh Badrud tetapi tokoh lain. Hal tersebut terbukti pada tokoh perempuan bernama Asih. Ia adalah seorang muslim yang taat menjalankan perintah Allah. Penampilannya berkerudung ditambah lagi kemampuan mengajinya tidak diragukan lagi sebagaimana dalam penggalan novel berikut.

"Sejak kapan Sampeyan pakai baju?"

"Sejak dulu kan?"

"Maksudku, pakai rok."

"Ooh...ini. tiga bulan lalu. Aku kan ngajar di TPA dekat kosku. Waktu itu aku masih pakai celana, trus diprotes sama murid-muridku. Eh, Bu, Ibu kan wanita. Celana kan untuk pakaian lelaki. Trus dia nyebutin ayat Al Quran yang isinya tentang cara berpakaian. Wah, ternyata dia anak ustad. Orangtuanya menaruh di masjid biar dia bersosialisasi dengan orang lain. Yah, sejak itu aku pakai rok. Pakai jilbab kalau ngajar ngaji dan berpakaian jauh" (Kristina, 2003: 36). 
Struktur penceritaan tentang kehidupan orang agamis ditampakkan dalm novel Homoseks Ketemu Tuhan karya Rini Kristina. Isi cerita yang jalin-menjalin memperkuat bukti bahwa novel ini memang dominan dalam unsur religiositasnya.

Tokoh perempuan yang lain bernama Hamidah yang merupakan saudara Asih memiliki keinginan untuk mengembangkan kegiatan mengaji di desa tersebut. Dengan kemampuan finansial yang dimiliki ia ingin mendiirkan sebuah tempat pendidikan Al Quran untuk memajukan desa itu agar keluar dari kebodohan warganya. Pernyataan tersebut sebagaimana tertuang dalam kutipan novel berikut.

Ia lupa menceritakan punya gawenya pada Asih. Esoknya baru ia ungkapkan, ketika seisi rumah berkumpul di depan tivi sambil menunggu azan maghrib.

"Aku ingin membentuk TPA di sini. Nanti kamu bantu aku muruk ngaji ya?"

"Sudah ada Yu, seorang warga baru yang merintisnya. Sudah berjalan dua minggu."

Hamidah terlongong sejenak. Kemudian bibirnya yang tipis tersenyum.

"Baguslah kalu begitu. Siapa yang muruk?"

"Ustad Badelut," clemong Danang yang tengah memakai sarung (Kristina, 2003: 38).

Berdasarkan kutipan di atas terbukti bahwa tokoh perempuan bernama Hamidah pun memiliki religiositas yang tidak dapat diremehkan. Asih juga mendukung keinginan saudaranya itu.

Bukti lain dikisahkan pada tokoh Hamidah yang berperilaku sebagai seorang muslim yang berpedoman kepada agamanya. Dalam kehidupan sehari-hari Hamidah ia berserah diri kepada Tuhannya merasuk dalam pikirannya sebagaimana kutipan berikut.

Hamidah tak bergeming, abadi dalam lamunannya, sejak dua jam yang lalu. Mulutnya mendesah, menyebut nama pemuda.

"Badrud.......

Kemudian asma Sang Pencipta meluncur lepas setengah memekik.

"Allah.......

begitu berulang kali. Nama pertama menyesakkan dada. Yang kedua untuk mengatasi gejolaknya. Sebagai penenang jiwanya. Setiap kali ia teringat pemuda itu, setiap kali ia menyebut nama
Tuhannya. Hamidah tidak mau hatinya dikuasai nama atau cinta apapun melebihi batas nama atau cinta terhadap DIA (Kristina, 2003: 70-71).

Berdasarkan kutipan tersebut terbukti bahwa Tuhan adalah segala-galanya bagi Hamidah. Ia tidak mau cinta dunia mengalahkan cinta kepada Tuhannya. Penerapan dalam hidup pun tecermin sikap hidup agamis. Ia selalu berpedoman kepada agama Allah dalam mengambil tindakan dan keputusan dalam bentuk apapun. Hal itu dibuktikan dari pengisahan tentang tingkah laku tokoh Hamidah dan bagaimana kehidupan sosialnya dalam masyarakat.

Diceritakan pada bagian lain yang berlandaskan kepada kitab Allah, yakni Quran. Tokoh-tokoh dalam novel Homoseks Ketemu Tuhan selalu menggunakan akal sehatnya untuk berpijak pada agama Allah. Hal tersebut sebagaimana dalam kutipan berikut.

Dalam Al Qur'an disebut adanya mimpi buruk dan ru'yat. Mimpi buruk yang campur aduk dan kabur. Seperti yang dijelaskan ahli ilmu jiwa modern di atas. Sedangkan ru'yat adalah mimpi yang benar di mana Allah menyampaikan wahyu atau ilham kepada para Nabi, Rasul, dan hamba-hamba-Nya yang lain, atau memberitahu mereka sesuatu yang akan terjadi pada masa datang.

Contohnya adalah mimpi Nabi Ibrahim as bahwa ia menyembelih putranya Nabi Ismail as. Mimpi yang dilihat raja Mesir tentang tujuh ekor sapi betina yang gemuk-gemuk dimakan tujuh ekor sapi yang kurus-kurus, dan tujuh butir (gandum) yang hijau dan tujuh butir lainnya yang kering (Kristina, 2003: 86).

Hamidah sebagai tokoh utama perempuan selalu memikirkan kemajuan desanya yang disebut "dukuh larangan itu". Ia ingin masyarakat yang tinggal di lingkungan desa tersebut makin lama makin meninggalkan kebodohan yang diceritakan telah mengakar dalam masyarakat itu. Ia ingin memberikan pemahaman agama yang jelas kepada masyarakat yang mayoritas awam itu sebagaimana terkandung dalam penggalan novel berikut.

Lebih dari itu, ia ingin memberikan pemahaman kepada masyarakat desanya, bahwa wanita tidak harus menunggu. Wanita yang memulai melamar pria bukanlah suatu aib yang memalukan, 
yang najis. Itu hanya adat, anggapan sebagian besar orang.

Yang terjadi pada sebagian besar gadis di desanya, bahwa mereka mengharap jodoh datang dengan sendirinya. Mereka ingin menikah, namun tetap ndhuwel di rumah.

Belum puas. Sekali lagi dibacanya kisah tentang Siti Khadijah, istri Rasulullah Muhammad. Wanita seagung beliau, dan melamar lelaki semulia Rasulullah, atau kisah Nabi Yusufyang dicintai Siti Zulaikha. Kenapa terjadi kepada Rasulullah? Tak lain, sebab beliau adalah tauladan umat Islam. tak pelak lagi, kisah itu bagian dari pengajaran Allah tentang tata cara perjodohan (Kristina, 2003: 90).

Nilai religiositas pada tokoh Badrutd yang telah menjadi guru mengaji di desa itu memiliki niat tidak hanya sampai di situ dalam mengabdikan hidupnya untuk beribadah. Ia ingin mengembangkan kegiatan mengaji di desa itu dan membangun perpustakaan.

Tidak hanya itu, Badrud pun dalam kesadagrannya pernah menjadi kaum homoseks selalu berpikir mengenai jalan keluar dari kesalahan itu. Badrud yang diceritakan dalam novel dikelilingi perempuan cantik seperti Hamidah dan Asih memiliki peenungan atas statusnya sebagai seorang homoseks pada masa lalunya di SMA. Ia menggunakan pikiran logisnya terkait permasalahan ini sebagaimana tampak dalam kutipan novel berikut.

Menurut ketentuan Allah yang termaktub dalam rumus fisika (sebagai gambaran tentang interaksi laki-laki dan perempuan). Hanya ion yang bermuatan beda yang bisa menghasilkan potensial/tegangan sebaliknya, ion yang bermuatan sama (ion positif bertemu ion positif atau ion negatif bertemu ion negatif) akan saling tolak-menolak.

Namun kenyataannya pada manusia tidaklah demikian. Percintaan sejenis itu ibarat memaksakan penyatuan yang tidak mungkin bersatu. Sama saja dengan melawan kodrat Allah. Namun, barang siapa menyimpang dari hukum-NYA, bagaikan membuat bangunan yang rapuh. Yang sebentar saja akan hancur.

Sebagai pemiliki jiwa manusia, tentu Allah lebih tahu teguran macam apa untuk menyadarkan manusia.
Kedatangan Jalil dengan membawa undangan nikah dan Hamidah yang mengaku membaca diarinya (Kristina, 2003: 134-134).

Berdasarkan kutipan di atas jelas terbukti bahwa novel Homoseks Ketemu Tuhan karya Rini Kristina ini memang benar-benar novel Islami dengan nilai religiositas tinggi. Mengenai permasalahan kaum homoseks di desa Cengkehan yang merupakan efek negatif dari kedatangan ilmuwan dari Jerman selalu berusaha bertakwa dengan mendasarkan seluruh hidupnya perintah Allah.

Tidak hanya hubungan kaun homoseks, tetapi juga hubungan dengan lain jenis, antara laki-laki dengan perempuan. Dikisahkan bahwa tokoh Lilis dengan Jalil langsung menikah tanpa ada pacaran seperti lpemuda masa kini. Budayabudaya Islami dominan menjadi tolok ukur pandangan hidup tokoh-tokoh dalam novel Homoseks Ketemu Tuhan karya Rini Kristina.

Dada Badrud berdebar tatkala jari Hamidah mengelus punggungnya. debaran aneh yang mampu menghentikan isaknya. Rasa yang baru sekali ini dirasakan ketika berdekatan dengan wanita. Darahnya terasa panas dan mengaliri sekujur tubuhnya. Memberikan rasa hangat. Lama Badrud menikmati rasa itu. Sementara debaran jantungnya kian kencang.

Ugh. Tiba-tiba Badrud menepiskan tubuh Hamidah dengan kasar.

"Ada apa Badrud?"

"Jangan Hamidah. Ini dosa."” gumam Badrud risau.

"Bukankah kau nggak punya birahi pada wanita?" cetus Hamidah heran. Badrud tak menjawab. Keduanya bersitatap. Lama. Sorot Hamidah menyimpan tanya, juga suatu harapan. Badrud tak kuasa menahan tatapan Hamidah (Kristina, 2003: 148).

Dalam kutipan di atas terbukti bahwa pengakuan dosa akan berpelukannya antara seorang laki-laki dengan perempuan bukan muhrim. Badrud merasakan kenormalan seksualnya ketika sedang berpelukan dengan hamidah.

Ketika mengetahui ia kembali "normal", tak henti-hentinya ia bersyukur atas segala pertolongan Allah akan kelainan seksualnya. Akhirnya usahanya untuk kembali ke jalan yang benaryang 
diperintahkan Allah kepadanya terjawab dudah. nilai religiositas Badrud saat bersyukur tersebut sebagaimana terkandung dalam penggalan novel brikut.

Hamidah...segala rasa yang ada terhadapnya. Sakit, cemburu, juga cinta. Ah, akhirnya rasa itu muncul lagi setelah menempuh perjalanan panjang berupaya kembali ke fitrahnya. Keyakinan pada sunnatullah, mengingat azab Allah, juga rasa galau yang erat menemaninya selama ini adalah pemicu semangat untuk kembali ke jalan yang lurus. Tentu dibarengi doa.

"Alhamdulillah akhirnya aku mampu" (Kristina, 2003: 148-149).

Di samping Badrud ada pula tokoh lain bernama Pak Lontar yang homoseks tetapi berupaya penuh untuk kembali ke jalan yang benar. Ia berusaha keras untuk bisa mengaji dan mengamalkan perintah Allah.

\section{PENUTUP}

Novel Homoseks Ketemu Tuhan karya Rini Kristina mengandung nilai religiositas yang tinggi. Nilai-nilai kehidupan itu tersaji melalui kritik tajam dan sindiran yang ditampilkan melalui tokoh-tokohnya.

Nilai religiositas yang mencolok dalam novel Homoseks Ketemu Tuhan karya Rini Kristina ini adalah panggilan agar pembaca menyadari hidupnya sebagai makhluk yang lemah, yang mau berserah diri kepada Allah, Sang Pencipta. Khususnya kepada orang yang termasuk kaum homoseks atau lesbian agar sadar untuk kembali kepada fitrahnya.

\section{REFERENSI}

Atmosuwito, Subijantoro. 2010. Perihal Sastra \& Religiusitas dalam Sastra. Bandung: Sinar Baru Algesindo.

Faruk. 2003. Pengantar Sosiologi Sastra dari Strukturalisme Genetik sampai PostModernisme. Yogyakarta: Pustaka Pelajar.

Jabrohim (Ed). 2003. Sosiologi Sastra: Beberapa Konsep Pengantar. Yogyakarta: Hanindita.

Kristina, Rini. 2011. Homoseks Ketemu Tuhan. Bantul: Kreasi Wacana.

Luxemburg, Jan Van dkk. Pengantar Ilmu Sastra. Jakarta: Gramedia.

Pradotokusumo, Partini Sardjono. 2005. Pengkajian Sastra. Jakarta: Garmedia.

Ratna, Nyoman Kutha. 2003. Paradigma Sosiologi Sastra. Yogyakarta: Pustaka Pelajar.

Ratna, Nyoman Kutha. 2004. Teori, Metode, dan Teknik Penelitian Sastra. Yogyakarta: Pustaka Pelajar.

Rosidah, Faiqotur. 2011. Tradisi Pesantren dalam Novel Remaja Berlatar Pesantren. Makalah Komprehensif. Surabaya: PPS Unesa (tidak diterbitkan).

Sitanggang S.R.H. dkk. 2003. Religiusitas dalam Tiga Novel Modern: Kemarau, Khotbah di Atas Bukit, dan Kubah. Jakarta: Pusat Bahasa Depdiknas.

Supratno, Haris. 2010. Sosiologi Seni. Surabaya: Unesa University Press. 